NBER WORKING PAPER SERIES

\title{
MOSTLY HARMLESS REGULATION? ELECTRONIC CIGARETTES, PUBLIC POLICY AND CONSUMER WELFARE
}

\author{
Donald S. Kenkel \\ Sida Peng \\ Michael F. Pesko \\ Hua Wang \\ Working Paper 23710 \\ http://www.nber.org/papers/w23710 \\ NATIONAL BUREAU OF ECONOMIC RESEARCH \\ 1050 Massachusetts Avenue \\ Cambridge, MA 02138 \\ August 2017, Revised March 2018
}

We acknowledge funding from a seed grant for collaborations between Cornell University-Ithaca and Weill Cornell Medical College faculty and from National Institutes of Health grants to the University of Illinois-Chicago (CA U01-154254, 1U01CA154248-04, and R01DA045016). We thank Michael French and participants at an iHEA/AEA session, and seminar participants at Cornell's health economics workshop for helpful comments. The views expressed herein are those of the authors and do not necessarily reflect the views of the National Bureau of Economic Research.

NBER working papers are circulated for discussion and comment purposes. They have not been peer-reviewed or been subject to the review by the NBER Board of Directors that accompanies official NBER publications.

(C) 2017 by Donald S. Kenkel, Sida Peng, Michael F. Pesko, and Hua Wang. All rights reserved. Short sections of text, not to exceed two paragraphs, may be quoted without explicit permission provided that full credit, including $\odot$ notice, is given to the source. 
Mostly Harmless Regulation? Electronic Cigarettes, Public Policy and Consumer Welfare Donald S. Kenkel, Sida Peng, Michael F. Pesko, and Hua Wang

NBER Working Paper No. 23710

August 2017, Revised March 2018

JEL No. I12

\begin{tabular}{|c|c|}
\hline \multicolumn{2}{|c|}{$\underline{\text { ABSTRACT }}$} \\
\hline \multicolumn{2}{|c|}{$\begin{array}{l}\text { Electronic cigarettes are a less harmful alternative to combustible cigarettes. We analyze } \\
\text { e-cigarette choices in an online experimental market. Our data and mixed logit model capt } \\
\text { sources of consumer optimization errors: over-estimates of the relative risks of e-cigaret } \\
\text { present bias. Our novel data and policy analysis make three contributions. First, our pre } \\
\text { about e-cigarette use under counter-factual policy scenarios provide new informatio } \\
\text { current regulatory tradeoffs. Second, we provide empirical evidence about the role co } \\
\text { optimization errors play in tobacco product choices. Third, we contribute to behavioral } \\
\text { analysis of policies that address individual optimization errors. }\end{array}$} \\
\hline Donald S. Kenkel & Michael F. Pesko \\
\hline Department of Policy Analysis & Department of Economics \\
\hline and Management & Andrew Young School of Policy Studies \\
\hline College of Human Ecology & PO Box 3992 \\
\hline Cornell University & Atlanta, GA 30302-3992 \\
\hline Martha Van Rensselaer Hall & Georgia \\
\hline $\begin{array}{l}\text { Ithaca, NY } 14853-4401 \\
\text { and NBER }\end{array}$ & mpesko@gsu.edu \\
\hline dsk10@cornell.edu & Hua Wang \\
\hline & Department of Policy Analysis \\
\hline Cornell University & MVR Hall \\
\hline 104 Walnut street & Cornell University \\
\hline Ithaca, NY 14850 & Ithaca NY 14853 \\
\hline sp947@cornell.edu & hw227@cornell.edu \\
\hline
\end{tabular}




\section{Introduction}

Electronic cigarettes and other vaping devices provide users with a vapor that contains nicotine without the combustion-generated toxicants in tobacco smoke. Vaping is not harmless but poses much lower risks than smoking. ${ }^{1}$ The vaping market has rapidly evolved. The first modern vaping products were introduced in U.S. markets around 2007. Annual sales grew rapidly from \$20 million in 2008 to $\$ 500$ million in 2012 to $\$ 6.6$ billion in 2018 . General retailers and specialized vape shops now offer a range of disposable and refillable vaping products in flavors including tobacco, menthol, fruit and candy. In 2016 data for adults, 11 percent of current smokers, 19 percent of recent (past-year) former smokers, and four percent of non-recent former smokers regularly vape, compared to 0.6 percent of never smokers. ${ }^{2}$

Public policy towards vaping is also evolving. After an unsuccessful Food and Drug Administration (FDA) effort in 2008 to regulate vaping products as medical devices, until 2016 vaping products were regulated as ordinary consumer products. In May 2016, the FDA issued a rule phasing in regulation of vaping products as tobacco products (FDA 2016). In addition to the FDA, states, counties, and municipalities have been regulating e-cigarettes as well. For example, by the end of 2018, 9 states had enacted e-cigarette taxes and 12 states had enacted comprehensive indoor vaping restrictions in place for restaurants, bars, and private workplaces (CDC STATE System).

The challenge for public policy is to craft e-cigarette regulations that do more good than harm. Smoking combustible cigarettes remains the leading preventable cause of death in the U.S. (U.S. Department of Health and Human Services 2014). From the perspective of public health, encouraging smokers to switch to vaping is a harm reduction strategy that could substantially reduce smokingrelated mortality and morbidity (Royal College of Physicians 2016). Adult smokers have been found to

\footnotetext{
${ }^{1}$ Section 2 below provides more discussion of the evidence on the relative risks of vaping and smoking.

${ }^{2}$ Authors' calculations from the 2016 National Health Interview Survey.
} 
significantly value e-cigarette products that are effective smoking cessation aids and that are healthier options (Marti et al. 2019). Harm reduction - such as providing clean needles to intravenous drug users - is an established part of public health policy, but its application to tobacco policy has been controversial. Tobacco policy makers often emphasize the importance of preventing youth smoking initiation, a goal which might be undercut if vaping serves as a gateway to future smoking (U.S. Department of Health and Human Services 2016). However, encouraging adult smokers to quit is also a very promising route to improve public health and a recent randomized control trial found that smokers given vaping products achieved biometrically-validated 1 year quit rates double that of smokers given nicotine replacement therapy (Hajek et al. 2019). A simulation model predicts that under a wide range of plausible parameters, the public health benefits of increased smoking cessation due to vaping outweigh the health costs of increased smoking initiation; the baseline estimate is that compared to a counterfactual with no vaping products, the availability of vaping products reduces the health consequences of smoking by 20 percent (Levy et al. 2017). In a recent announcement of a shift in tobacco regulation priorities, the FDA Commissioner emphasizes that compared to the health hazards of combustible cigarettes, "less harmful products ... under FDA's oversight, could be part of a solution." (Gottlieb 2017)

From the perspective of welfare economics, it is important to consider the impact of e-cigarette regulations on consumer welfare, not just public health. Indeed, from the perspective of neoclassical welfare economics anti-smoking regulations might reduce consumer welfare while improving public health. However, from the perspective of behavioral welfare economics regulations to reduce smoking can improve the welfare of consumers who make optimization mistakes (Jin et al. 2015, Cutler et al. 2016, Levy, Norton and Smith 2016). Similarly, regulations that encourage non-optimizing smokers to become vapers could increase their experienced utility and thus social welfare. 
In this article we analyze stated preference data from an online discrete choice experiment (DCE) where adult smokers made hypothetical choices between e-cigarettes, combustible cigarettes, and a nicotine-replacement product. DCEs are commonly used in marketing research and economics to provide predictions of consumer demand in policy-relevant scenarios that are not yet observed in actual markets (e.g., Kesternich, Heiss, McFadden, and Winter 2013). In our DCE the attributes of the ecigarette were varied experimentally to match potential FDA regulations and state policies. We use the data to estimate the parameters of a random utility-maximization (RUM) model.

Our data and model capture two reasons that smokers might fail to make fully optimizing decisions. First, smokers might over-estimate the risks of vaping and nicotine replacement products relative to the risks of smoking combustible cigarettes (Viscusi 2016). Responses to our online survey provide individual-level measures of the perceived risks, which we include as a product attribute in the RUM model. Second, smokers might be subject to present bias and make time-inconsistent decisions about quitting (Gruber and Koscegi 2001). Responses to our online survey also provide measures of present bias. We assume that the smoker's decision utility reflects a set of valuation weights that capture present bias (Allcott, Mullanaithan, and Taubinsky 2014). This leads to a mixed logit/ random coefficients model, where the valuation weights are a function of the smoker's interest in a commitment contract to help them make time-consistent choices to quit.

We use our novel data and estimated model of e-cigarette choices to conduct policy analysis and behavioral welfare analysis. We make three contributions. First, our predictions about e-cigarette use under counter-factual policy scenarios provide new information about regulatory tradeoffs currently being considered. Unlike much of the current literature on e-cigarettes that uses geographical variation in minimum legal purchase age laws (Friedman 2015, Abouk and Adams 2017, Dave, Feng, and Pesko 2019) and indoor vaping restrictions (Cooper and Pesko 2017), our study considers several regulations under consideration but not enacted at the state or federal level. Second, we provide empirical evidence 
about the role consumer optimization errors play in tobacco product choices. We find that risk perceptions have a significant negative impact on e-cig choices while present bias has a significant positive impact. As a result, it becomes crucial to take those behavior factors into consideration when computing compensating variation or making policy simulations. Third, we contribute to a recent line of research that conducts behavioral welfare economics of policies that address individual optimization errors. $^{3}$

Under pre-2016 FDA regulation market conditions our model predicts that 16 percent of current smokers will choose e-cigarettes versus 71 percent who will choose combustible cigarettes. ${ }^{4}$ We find that consumers' stated preferences respond to the experimental variation in the availability of flavors, strong health warning labels, and e-cigarette prices. In public policy counterfactuals, our model predicts that FDA regulations and state e-cigarette taxes could reduce the fraction who choose e-cigarettes to as low as 13 percent. We also find evidence that misperceptions of the risks of e-cigarettes and naiveté about time inconsistency leads to under-consumption of e-cigarettes relative to combustible cigarettes. In a descriptive counterfactual, among consumers who do not make these optimization errors, the fraction who choose e-cigarettes is 32 percent, double the rate under pre-FDA regulation conditions.

We analyze the welfare impacts of alternative policies on experienced utility, based on the estimated preferences of consumers who are well-informed about product risks and who are sophisticated about their time inconsistency. The compensating variations (CVs) in income for the policies calculated with respect to decision utility substantially understate the CVs calculated with respect to experience utility. Compared to standard cost-benefit analysis, our behavioral welfare

${ }^{3}$ Chetty (2015) provides an overview of behavioral public economics. Recent behavioral welfare economic studies examine consumer choices across various domains including prescription drug insurance (Ketcham, Kuminoff and Powers 2016), energy-efficient appliances (Allcott and Taubinsky 2015), and smoking (Jin, Kenkel, Liu and Wang 2015).

${ }^{4}$ The remaining 13 percent choose the nicotine replacement product. 
economics analysis leads to much larger estimates of the costs of policies that discourage e-cigarette use or the benefits of policies that encourage e-cigarette use.

The remainder of the article is organized as follows. Section 2 provides background about vaping and its regulation. Section 3 presents the empirical model and the expressions for the compensating variations used in the welfare analysis. Section 4 describes the experimental methods of the DCE and the measurements of consumer optimization errors. Section 5 presents reduced-form results from linear probability and multinomial logit models. We also present a multinomial logit model that combines the stated preference data from the DCE and revealed preference data on subjects' actual use of the tobacco products. Section 6 presents the results of the mixed logit model and the policy analysis and behavioral welfare analysis. Section 7 concludes.

\section{Background about Vaping and Its Regulation}

For the individual user, the health risks of vaping are much lower than the health risks of smoking. The vapor from most e-cigarettes contains the addictive chemical nicotine, but the major health risks of smoking are linked to the other constituents of tobacco smoke including carbon monoxide and combustion-generated toxicants. The FDA has approved nicotine replacement products including the nicotine inhaler but not e-cigarettes - as safe and efficacious medical products for smoking cessation. Goniewicz et al. (2014) find that e-cigarette vapor contains some of the same toxicants as tobacco smoke, but at levels that are comparable to the nicotine inhaler and that are $1 / 9$ to $1 / 450$ the levels in cigarette smoke. ${ }^{5}$ Depending upon different assumptions about the dose-response relationships for the toxicants, Viscusi (2016) suggests that the risk of vaping is about $1 / 100$ to $1 / 1000$ the risk of smoking. The Royal College of Physicians $(2016$, p. 5) concludes that: "The main culprit is

\footnotetext{
${ }^{5}$ Research and media reports about alarming levels of formaldehyde in e-cigarette vapor have been shown to be misleading because they "were generated by subjecting e-cig apparatus to conditions which human smokers do not use" (Farsalinos et al. 2015, Hajek et al., 2014).
} 
smoke and, if nicotine could be delivered effectively and acceptably to smokers without smoke, most if not all of the harm of smoking could probably be avoided." The nicotine in e-cigarette liquid and vapor poses some risks. The direct ingestion of vaping liquid poses a risk for accidental poisonings. Nicotine exposure during the fetal period is harmful. Studies in animals suggest that nicotine exposure during adolescence might also hurt brain development, but this is a difficult question to study in humans (Royal College of Physicians 2016, p. 59). Because there is relatively little information about the risks of longterm use of nicotine in general and e-cigarettes in particular, the policy statements of the American College of Physicians (Crowley 2015), the American Heart Association (Bhatnagar et al. 2014), and the American Cancer Society (2018) stress the uncertainty about estimates of the risks of e-cigarettes. ${ }^{6}$

In addition to the risks for the individual user, the FDA must take into account tobacco products' impact on public health through their impacts on cessation and initiation. The 2009 Tobacco Control Act (TCA) establishes the public health standard for FDA regulation of tobacco products; in 2016 the FDA issued a regulation that deems e-cigarettes to be tobacco products under the TCA. Most e-cigarettes are sold to current and former smokers, many of whom report that they used e-cigarettes to quit smoking (Schoenborn and Gindi 2015, Biener and Hargraves 2014). However, if e-cigarette users continue to smoke combustible cigarettes instead of completely quitting, the availability of e-cigarettes might harm public health. As discussed above, another public health concern is that e-cigarettes might act as a gateway to combustible cigarettes so their availability might increase youth smoking initiation. The TCA requires the FDA to make regulatory decisions about e-cigarettes that balance the lower risks to individual users with these public health concerns.

The 2016 FDA deeming regulation requires e-cigarettes to carry health warning labels and requires e-cigarette manufacturers to submit marketing applications. In 2017, the FDA extended the

\footnotetext{
${ }^{6}$ For additional discussion and different interpretations of the evidence on the risks of ecigarettes, see the point/counter-point by Kenkel (2016) and Ribisl, Seidenberg, and Orlan (2016).
} 
original two to three year phase-in period for premarket applications to August 2022 (FDA 2017). However, in Nov. 2018 the FDA announced that due to concern about high rates of e-cigarette use among youth, it was revisiting this compliance timeline for e-cigarette products that are flavored with flavors besides tobacco, mint, and menthol (FDA 2018). The FDA indicated an intention to no longer permit the sale of these flavored e-cigarette products in non-age-restricted locations and required the implementation of a rigorous age verification requirements for online purchases. The FDA also indicated interest in regulating the sale of mint and menthol for all tobacco products in the future. They warned that if e-cigarette use among youth does not substantially decline, they would consider potentially eliminating application enforcement discretion to any currently marked e-cigarette product, which "would result in the removal of ALL such products from the marketplace (FDA 2018)."

E-cigarette manufacturers also have the option to submit an application to the FDA to market their products through the modified risk tobacco product (MRTP) pathway. MRTP status would allow manufacturers to market and advertise e-cigarettes as lower risk than cigarettes. There is little track record to predict whether an MRTP application for a vaping product would succeed. In 2014 Swedish Match applied to market snus smokeless tobacco products as MRTPs and included a proposal to replace the currently required warning with a label that the products are lower-risk than other tobacco products. In its first actions on an MRTP application, in December 2016 the FDA denied the request to remove the current warning label. The FDA deferred final action on the Swedish Match MRTP application and requested that the company submit an amended application to support issuance of a modified risk order. The most recent amended application was submitted in January, 2019 (FDA 2019). In addition to federal FDA regulations, e-cigarettes are also the subject of state and local policies, most notably taxes. As of January 1 2019, nine states tax e-cigarettes at rates that are generally lower than taxes on combustible cigarettes (CDC STATE System). D.C. taxes e-cigarettes and combustible cigarettes at the same rate, currently $\$ 4.94$ per pack. State Medicaid programs are required to provide 
insurance coverage that subsidizes the cost of approved nicotine replacement products, but to date these programs do not cover e-cigarettes.

As will be discussed in more detail in section 4 below, we designed the experimental conditions of our DCE to cover a range of possible e-cigarette policies including: health warning and reduced-risk labels; a ban on the availability of flavors; and taxes or subsidies that change e-cigarette prices.

\section{Empirical Model and Welfare Expressions}

\section{Empirical Model}

In this section we develop an empirical model of a consumer's choice between three tobacco products: e-cigarettes, combustible cigarettes, and a nicotine replacement product. In the standard RUM model, individual i's utility from choosing tobacco product $\mathrm{j}, \mathrm{U}_{\mathrm{ij}}$, is decomposed into the observable utility component $\mathrm{V}_{\mathrm{ij}}$ that is explained by observed product attributes and an unobserved random utility component $\epsilon_{\mathrm{ij}}$ :

$$
U_{i j}=V_{i j}+\epsilon_{i j}
$$

The consumer chooses the tobacco product that yields the highest utility:

$$
U_{i j} \geq U_{i k} \quad \forall k \neq j
$$

The probability that consumer $\mathrm{i}$ chooses tobacco product $\mathrm{j}$ is thus given by:

$$
P_{i j}=\mathbb{P}\left(\epsilon_{i k}-\epsilon_{i j} \leq V_{i j}-V_{i k}, \forall k \neq j\right)
$$

The assumptions that $\epsilon_{\mathrm{ij}}$ is i.i.d. across $\mathrm{j}$ and follows the type I extreme value distribution leads to the logit specification:

$$
P_{i j}=\frac{e^{V_{i j}}}{\sum_{k=1}^{J} e^{V_{i k}}}
$$


The empirical model captures two sources of consumer optimization errors. First, the individual's subjective perceived risk of each product - rather than the objective product risk -- is one of the product attributes that determines $V_{\mathrm{ij}}$. Second, we introduce an individual-specific preference weight $\Gamma_{\mathrm{i}}$ into the discrete choice model. In the spirit of the reduced-form approach to behavioral welfare economics (Mullanaithan, Schwartzstein and Congdon 2012), Allcott et al. (2014) show that including the preference weight $\Gamma$ is a flexible approach that captures a number of behavioral biases, including present bias and naiveté about present bias. For example, $\Gamma_{i}<1$ captures a consumer $i$ with present bias who under-weights the lifetime utility loss from the future health consequences of their use of a risky tobacco product.

In the empirical model we assume the observable component of utility $V_{i j}$ is a linear function of a vector of product attributes $X_{i j}$ multiplied by the preference weight $\Gamma_{i}$, so the consumer's decision utility is given by: ${ }^{7}$

$$
U_{i j}^{\text {decision }}=\Gamma_{i} X_{i j} \beta+\epsilon_{i j}
$$

The preference weight $\Gamma_{i}$ is a function of observed characteristics $Z_{i}$ and an unobservable random component $\delta_{\mathrm{i}}$ :

$$
\Gamma_{i}=Z_{i}^{\prime} \alpha+\delta_{i}
$$

Equations (5) and (6) lead to a mixed logit/ random coefficients specification. In addition to incorporating $\Gamma$, the mixed logit specification is a highly flexible model that allows individual heterogeneity to interact with product characteristics. It also relaxes the independence of irrelevant

${ }^{7}$ The product attributes $X_{i j}$ depend on consumer index $i$ because they include the individuallevel subjective product risks. The vector $X_{\mathrm{ij}}$ also includes alternative-specific intercept terms that capture the average utility from each product. Except for subjective product risk, the other product attributes included in $X_{i j}$ are alternative-specific and do not vary across individuals. 
alternatives assumption of the multinomial logit model (Train 2002). In our mixed logit model, the decision utility function is re-written as:

$$
\begin{aligned}
U_{i j}^{\text {decision }} & =\Gamma_{i} \sum_{k=1}^{K} X_{i j k} \beta_{k}+\epsilon_{i j} \\
= & Z_{i}^{\prime} \alpha \sum_{k=1}^{K} X_{i j k} \beta_{k}+\delta_{i} \sum_{k=1}^{K} X_{i j k} \beta_{k}+\epsilon_{i j} \\
= & \underbrace{\sum_{k=1}^{K} X_{i j k} Z_{i}^{\prime} \alpha \beta_{k}}_{\text {fixed coefficients }}+\underbrace{\sum_{k=1}^{K} X_{i j k} \beta_{k} \delta_{i}}_{\text {random coefficients }}+\epsilon_{i j}
\end{aligned}
$$

In the mixed logit model given by equation (7), consumer optimization errors are captured by the interaction terms between $Z_{i}$ (the determinants of the preference weights $\Gamma_{i}$ ) and $X_{i j t}$ (the product attributes). Our empirical model tests the predictions that through $\Gamma_{i}$ naiveté about present bias leads consumers to under-value product attributes such as warning labels that influence future period utility. The model also allows for optimization errors that arise because the consumer makes decisions based on his or her subjective risk (one of the product attributes) instead of the objective risk of the product choices.

\section{Welfare Expressions}

In section 6 below we use the results from our mixed logit model to predict consumer choices under policy counterfactuals and to conduct behavioral welfare economic analysis. The compensating variation (CV) in income with respect to decision utility is given by the standard expression derived by Small and Rosen (1981): ${ }^{8}$

$$
\mathbb{E}\left(C V_{i}^{\text {decision }}\right)=\frac{1}{\beta_{p}}\left\{\ln \sum_{k \in J} \exp \left(V_{i k 1}^{\text {decision }}\right)-\ln \sum_{j \in J} \exp \left(V_{i j 0}^{\text {decision }}\right)\right\}
$$

${ }^{8}$ McFadden (2017) shows that the standard parametric assumptions are not required; instead the welfare expression in equation (8) can be viewed as an approximation to the expression that follows from more basic assumptions. 
In equation (8), the subscript 0 or 1 indicates the absence or presence of a policy and $\beta_{\mathrm{P}}$ is the price coefficient so $1 / \beta_{p}$ is the marginal utility of income. Because equation ( 8 ) takes the expectation, it is written in terms of the observable utility component $\mathrm{V}_{\mathrm{ij}}$.

In our behavioral welfare economic analysis, we calculate the CV for a policy change with respect to experienced utility instead of decision utility. The possibility of consumer optimization errors means that the tobacco product choices based on decision utility do not necessarily lead to the highest experienced utility. Behavioral welfare economic analysis is therefore conducted with respect to consumers' experienced utilities (Mullainathan et al. 2012, Chetty 2015). Our analysis allows for two sources of optimization errors: consumer misinformation about tobacco product risks (one of the product attributes); and present bias captured by the preference weights $\Gamma_{i}$. Our calculations of the CVs that incorporate consumer optimization errors follow Leggett (2002) and Ketcham et al. (2016). ${ }^{9}$

We assume that the consumer chooses the tobacco product that provides the highest decision utility given by equation (7), but that the observable component $V_{i j}$ of the consumer's experienced utility depends on the objective risks and is not subject to present bias so $\Gamma=1$. The consumer's experienced utility from the choices that maximize decision utility is given by:

$$
\begin{aligned}
& \mathbb{E}\left(U_{i}\right)=\mathbb{E}\left[\max _{j}\left(U_{i j}^{\text {decision }}\right)\right] \\
&=\sum_{j=1}^{J} \int\left(V_{i j}+\epsilon_{i j}\right) F_{j}\left(V_{i j}^{\text {decision }}-V_{i 1}^{\text {decision }}+\epsilon_{i j}, \cdots, V_{i j}^{\text {decision }}-V_{i J}^{\text {decision }}+\right. \\
&\left.\epsilon_{i j}\right) d \epsilon_{i j}
\end{aligned}
$$

Subtracting this expression from the expression for experienced utility with the policy and dividing by the marginal utility of income as in equation (8) leads to:

$$
\begin{aligned}
& C V_{i}=\frac{1}{\beta_{p}}\left\{\ln \frac{\sum_{k \in J} \exp \left(V_{i k 1}^{\text {decision }}\right)}{\sum_{j \in J} \exp \left(V_{i j 0}^{\text {decision }}\right)}+\sum_{k \in J} \psi_{i k 1}^{\text {dec }}\left(V_{i k 1}-V_{i k 1}^{\text {decision }}\right)-\sum_{k \in J} \psi_{i k 0}^{\text {dec }}\left(V_{i k 0}-\right.\right. \\
& \left.\left.V_{i k 0}^{\text {decision }}\right)\right\}
\end{aligned}
$$

\footnotetext{
${ }^{9}$ For additional discussion and applications, see Allcott (2013) and Train (2015), who use a similar approach.
} 
where

$$
\psi_{i k 1}^{\text {dec }}=\frac{\exp \left(V_{i k 1}^{\text {decision }}\right)}{\sum_{m \in J} \exp \left(V_{i m 1}^{\text {decision }}\right)}
$$

Below we use equations (8) and (10) to calculate the CVs for policy counterfactuals with respect to decision utility and experienced utility.

\section{Data}

\section{Discrete Choice Experiment}

The data for our analysis are from a DCE included in an online survey conducted in December 2014 and January 2015. DCEs and other stated preference (SP) methods are used in contexts when it is difficult or impossible to examine consumers' revealed preferences (RP) in actual markets. For example, contingent valuation surveys are widely used to collect SP data on environmental quality and other nonmarket goods. DCEs are often used to examine consumers' preferences over policy-relevant product attributes that are not observed in actual markets. ${ }^{10}$ For example, in actual market conditions ecigarettes are available in a wide range of flavors, so it is impossible to identify the impact of a flavor ban on use. Reviews of SP methods lead to a broad but not universal consensus that they provide highquality data for policy analysis (Carson 2012, Hausman 2012, McFadden 2017).

The sample was recruited from the GfK (Knowledge Networks) online panel. GfK panel members sign up to participate in online surveys and receive GfK points which are redeemable for cash, merchandise, gift cards or game entries. The sample consisted of 1,148 current smokers: 505 aged 18 24 and 643 age 25 and over.

${ }^{10}$ DCEs are related to conjoint analysis, and some researchers use the two terms interchangeably. Louviere, Flynn and Carson (2010) stress that DCEs, but not conjoint analysis, are consistent with economic demand theory because they are based on the RUM model. 
In the DCE subjects made hypothetical choices between purchasing an e-cigarette, their usual brand of combustible cigarettes, or a nicotine replacement product. To be realistic many DCEs offer subjects an "outside alternative," which is often the option of making no purchase. All of the subjects in our DCE were current cigarette smokers who made frequent purchases of some tobacco product. In this context, the choice of purchasing their usual brand of combustible cigarettes is the outside alternative. The choice set presented in the DCE is a simplified version of the choice set smokers face each time they make an actual tobacco product purchase; multiple brands of e-cigarettes, combustible cigarettes, and nicotine replacement products are usually available at the same retail outlets and are even displayed together, e.g. at or behind the checkout counter. DCEs tend to be more reliable when the subjects are familiar with the products and have experience making choices between them (McFadden 2017, p. 162). An example choice scenario is available as Appendix Figure 1.

The DCE presented subjects with different choice scenarios where the product attributes of the e-cigarette were varied to correspond to possible FDA regulations and state policies: the availability of flavors other than tobacco/menthol; health warning labels; and price. The DCE used an orthogonal design that was balanced across attribute levels, so the variations of the e-cigarette attributes are uncorrelated.

The DCE included four warning label conditions on the e-cigarette: no label; a proposed FDA warning label; a modified risk warning label; and a strong warning label. The FDA proposed warning label was: "WARNING: This product contains nicotine derived from tobacco. Nicotine is an addictive chemical." This warning label, minus the part about "derived from tobacco" was adopted by the FDA action in 2016 and remains in place today. However, the FDA retains discretion to implement a stronger or modified risk warning label in the future, thus the policy significance of this choice scenario remains relevant. The modified risk warning label used in this DCE is the label proposed by Swedish Match in its MRTP application for its smokeless tobacco products: "WARNING: No tobacco product is safe, but this 
product presents substantially lower risks to health than smoking cigarettes." The strong warning label is the label voluntarily adopted by the manufacturer of MarkTen e-cigarettes and includes a long list of counter-indications, side effects, and risks. In the DCE, the combustible cigarette option included one of the warning labels currently required on cigarettes; the cigarette warning did not vary across the choice scenarios.

The DCE included three e-cigarette price conditions: $\$ 3, \$ 6$, and $\$ 9$. The $\$ 6$ condition approximated the average price of an e-cigarette product equivalent to a pack of combustible cigarettes. The price of the combustible cigarette alternative was the price per pack the subject reported usually paying for their usual brand of cigarettes. The price of the nicotine replacement product was $\$ 6$ for a package equivalent to a pack of cigarettes. The prices of the combustible cigarette and of the nicotine replacement product did not vary across the choice scenarios.

Out of the 24 possible combinations of attributes and conditions, each subject was presented with 12 choice scenarios. The design of the DCE is consistent with best practice guidelines for the number of attributes, levels, and choice scenarios (Bridges et al. 2011). The order of the choice scenarios was randomized across subjects. ${ }^{11}$ The 12 choice scenarios were chosen to maximize D-efficiency. ${ }^{12}$

Table 1 provides descriptive statistics about the subjects, their responses to the DCE, and their use of the tobacco products over the past year.

\section{Measuring Optimization Errors}

After the DCE, the online survey included questions to measure possible consumer optimization errors. The first set of questions measured subjects' perceptions of the risks of the different tobacco

\footnotetext{
${ }^{11}$ As reported in Pesko et al. (2016), we found no evidence that the order in which the warning labels were presented to subjects influenced the choices.

${ }^{12} \mathrm{D}$-efficiency is a metric based on the criterion to minimize the generalized variance of the parameter estimates. The D-efficiency of our DCE is 98 percent, relative to 100 percent that could be accomplished by asking about all 24 possible choice scenarios.
} 
products. ${ }^{13}$ We followed an approach used in previous research (Viscusi 1990, 2016) and asked users:

"Among 100 cigarette smokers (users of e-cigarettes), how many of them do you think will die from lung cancer, heart disease, throat cancer and all other illness because they smoke (use e-cigarettes)?" The responses provide a simple summary of the perceived lifetime risks of product use and can be compared to scientific estimates of the objective risks. The U.S. Department of Health and Human Services (2014, p. 666) estimates that the lifetime risk for a young adult smoker is 32 percent. Based on Viscusi's (2016) estimates from dose-response relationships and the other evidence discussed above in section 2 , the lifetime risks of e-cigarette use and use of a nicotine replacement product are approximately zero.

As can be seen in Table 2, subjects in our online sample tend to substantially over-estimate the risks of e-cigarettes and nicotine replacement products. On average subjects believe that the lifetime risks are: 30 percent for e-cigarette use; 46 percent for smoking; and 28 percent for the use of nicotine replacement products. The results are comparable to previous research on the perceived risks of ecigarette use (Viscusi 2016), smoking (Viscusi 1990), and nicotine replacement products (Shiffman et al. 2008).

The online survey included another set of questions to measure consumer time preference and time inconsistency. In one question subjects were told to suppose that they had won a prize of $\$ 1,000$ which they could claim immediately or after a wait of one year. In another question subjects were asked about a wait of one month. Subjects were asked to state the smallest amount of money that would convince them to wait. The questions are patterned after questions included in the 2006 wave of the

${ }^{13}$ Although the DCE choices included warning labels, the design of the online survey should minimize their influence on subjects' responses about product risk perceptions. At the beginning of the DCE, subjects were instructed that: "The FDA is studying whether a warning label is appropriate and what it should say....Our survey will ask you about several possible labels. When answering the questions, you should assume that the label you are asked about in the question reflects the FDA's labeling decision based on the best scientific evidence available." In the DCE, over the course of 12 scenarios each subject in the DCE saw each of the four warning label conditions three times, so any influences on their risk perceptions should approximately cancel out. 
1979 cohort of the National Longitudinal Survey of Youth (NLSY). If subjects are time-consistent exponential discounters their responses to the questions about waiting a year versus a month will imply the same annualized discount factor. If subjects have quasi-hyperbolic time preferences, the responses to the questions can be used to calculate the $\beta$-discount factor where $\beta<1$ implies present bias. ${ }^{14}$

Subjects in our online survey display present bias, with an average $\beta$-discount factor of 0.73 (Table 2). The estimated $\beta$ is less than 1 for 93 percent of our sample, implying that virtually all the subjects display present bias. By comparison, in their analysis of responses to the same questions included in the NLSY, Courtemanche et al. (2014) find an average $\beta$-discount factor of 0.8 with $\beta<1$ for 85 percent of the NLSY sample. Our results also compare well to the consensus estimate from experimental research that $\beta=0.7$ (Angeletos et al. 2001) and to results from the surveys reported in Newell and Siikamaki (2015a, 2015b). In an analysis of naturally occurring field data, Laibson, Maxted and Repetto's (2017) benchmark estimate of the discount factor is $\beta=0.5$.

Behavioral economic models of hyperbolic discounting make an important distinction between naïve consumers versus sophisticated consumers who recognize their present bias (Gruber and Koszegi 2001). Sophisticated present-biased consumers should be interested in using commitment strategies to overcome their time inconsistency. To measure naïveté/sophistication, our online survey described a commitment contract for smoking cessation like those offered on the stickK webpage: "When you sign up, you lay money on the line, say $\$ 50$, that you lose if your fail to meet the goal by the date that you agreed on." Subjects responded on a Likert scale from "not at all interested" to "extremely interested."

As shown in Table 2, 20 percent of subjects in our sample were at least somewhat interested in a commitment contract to quit smoking. By comparison, in a field experiment in the Philippines 11 percent of smokers took up an offer of a commitment contract for smoking cessation (Gine, Karlan and Zinman 2010). In further analysis, we compared the responses about $\beta$-discounting of the subjects who

\footnotetext{
${ }^{14}$ See equations (8) and (9) in Courtemanche, Heutel, and McAlvanah (2014).
} 
stated an interest in the commitment contract with those who were not interested. The average $\beta$ -

discount factor was 0.74 among those interested in the commitment contract compared to 0.725 among those not interested, a difference which was not statistically significant.

\section{Reduced-form Results}

\section{Linear Probability and Standard Logit Models}

Table 3 provide results from reduced-form linear probability models of e-cigarette choice and multinomial logit models of the probabilities of e-cigarette, combustible cigarette, and nicotine replacement product choice. To conserve space Table 3 only reports the multinomial logit results for the determinants of the probability of e-cigarette choice; full results are available upon request.

The results in the first two columns of Table 3 show that subjects are more likely to choose ecigarettes: when flavors other than tobacco/menthol are available; when there is not a warning label (the omitted category); and when the price is $\$ 3$ (the omitted category) compared to $\$ 6$, or $\$ 6$ compared to $\$ 9$. The linear probability model and multinomial logit model yield similar marginal effects (logit marginal effects in [ ]). Only the strong warning label voluntarily adopted by MarkTen has a practically and consistently statistically significant effect: from a sample mean of 13 percent e-cigarette choices, the strong warning label condition causes a six percentage point drop. Surprisingly, the results imply that the reduced-risk warning label discourages the choice of e-cigarettes, but the effect is small and statistically insignificant. Pesko et al. (2015) discuss additional reduced-form results from the DCE.

The reduced-form results also provide preliminary evidence that consumer optimization errors are important in tobacco product choices. Subjects who perceive higher mortality risks from e-cigarettes are less likely to choose e-cigarettes. Compared to a consumer who over-estimates the risk of ecigarettes to be 30 deaths per 100 users (the sample average subjective risk perception), a wellinformed consumer who correctly perceives the risk to be approximately zero is about three percentage points more likely to choose e-cigarettes. Subjects who do not display much present bias (as indicated 
by a $\beta$-discount factor greater than 0.9 ) are about as likely to choose e-cigarettes as subjects who display more present bias. (In results not reported but available upon request, we also find a statistically insignificant coefficient in a specification that instead of the indicator for $\beta>0.9$ uses the continuous variable $1-\beta$.$) However, subjects who express an interest in a commitment contract to quit smoking are$ substantially -- about nine percentage points -- more likely to choose e-cigarettes. The pattern of results suggests that because virtually all subjects show present bias, the useful empirical distinction is between naïveté versus sophistication. Accordingly, in our mixed logit model reported below we adopt the more parsimonious specification that only includes the measure of naïveté as a determinant of the preference weight $\Gamma{ }^{15}$ We provide further evidence of consumer optimization errors based on revealed preference data in Appendix Table 2. Similarly patterns are observed.

\section{Models that Combine Stated and Revealed Preference}

The third column of Table 3 reports the results of a logit model estimated using a combination of SP data from the DCE and RP data from subjects' responses about their prior use of e-cigarettes, combustible cigarettes, and nicotine replacement products. Our main analysis uses SP data from the DCE to explore variation in tobacco product attributes that is not observed in actual markets. However, RP data has the obvious advantage that it reflects actual consumer choices. The combination of SP and RP data is a way to exploit the strengths of each type of data: "The stated-preference data provide the

${ }^{15}$ Including the $\beta$-discount factor as a determinant of $\Gamma$ is less parsimonious because it adds nine interaction terms to the mixed logit model. The results from the less parsimonious mixed logit model are presented in Appendix Table 1. They are similar to the results for the more parsimonious model reported in Table 4. Augenblick, Niederle, and Sprenger (2015) argue that responses about time-dated monetary payments might not be suitable to identify preferences for time-dated consumption. This argument suggests another explanation for the pattern of our results: our online survey measured present bias over time-date monetary payments, but it measured naïveté in the specific context of the consumption of cigarettes. Under this explanation, the results for the commitment contract variable can still be interpreted as capturing the effects of some type of optimization error, but the results might be less informative about the specific role played by naïveté. 
needed variation in attributes, while the revealed-preference data ground the predicted shares in reality." (Train 2002, p. 157).

For the combined estimation we consider standard logit models for RP and SP data. We assume that the random error term for the RP data follows the type I extreme value distribution with scale parameter normalized to 1 , while the scale parameter for the SP data is given by $\lambda^{S P}$. The choice probabilities for the RP and SP data can then be written as:

$$
\begin{gathered}
P_{i j}^{R P}=\frac{\exp \left(\alpha_{j}+X_{i j}^{R P} \beta\right)}{\sum_{k=1}^{J} \exp \left(\alpha_{k}+X_{i k}^{R P} \beta\right)} \\
P_{i j}^{S P}=\frac{\exp \left(\lambda^{S P}\left(\alpha_{j}+X_{i j}^{S P} \beta\right)\right)}{\sum_{k=1}^{J} \exp \left(\lambda^{S P}\left(\alpha_{k}+X_{i k}^{S P} \beta\right)\right)}
\end{gathered}
$$

In the combined estimation we maximize the joint likelihood function:

$$
L\left(\alpha, \beta, \lambda^{S P}\right)=\sum_{i=1}^{N} \sum_{j \in C} y_{i j}^{R P} \log P_{i j}^{R P}+\sum_{i=1}^{N} \sum_{j \in C} y_{i j}^{S P} \log P_{i j}^{S P}
$$

The results are presented in the third column of Table 3 . The estimated parameter $\lambda^{\text {SP }}$ is close to 1 , suggesting that the scales in the RP and SP data are similar. The estimated coefficients on the tobacco product attributes show the same patterns as in the column (2) model based on SP data only. Overall, we interpret the results from the combined RP and SP model as supporting the usefulness of our SP data for policy analysis.

\section{Mixed Logit Results, Counterfactuals, and Welfare Analysis}

\section{Mixed Logit Results}

Table 4 presents the results of the mixed logit model given by equation (7). To estimate equation (7) we assume that the random coefficients $\delta_{i}$ follow the normal distribution, except for the coefficients on the price and risk variables which we assume follow the log normal distribution. We make 500 draws to construct the simulated likelihood function. The estimated parameters in Table 4 maximize the simulated likelihood function. 
Table 4 presents the estimated means and standard deviations of the random coefficients. The alternative-specific constant terms reflect the baseline utility from each tobacco product. We estimate that compared to combustible cigarettes, on average the alternatives of e-cigarettes and the nicotine replacement product (NRP) provide lower baseline utilities. Flavors increase the average utility from ecigarettes, while the strong warning label decreases the average utility from e-cigarettes. Higher prices also decrease the average utility from e-cigarettes.

The estimated standard deviations of the random coefficients show substantial heterogeneity. For example, although on average the baseline utility from e-cigarettes is negative, based on the estimated mean and standard deviation the e-cigarette-specific constant is positive for about 21 percent of the sample. Similarly, the estimates imply that while flavors increase utility on average, they decrease utility for 35 percent of the sample. This might reflect smokers who prefer e-cigarettes that are more similar to their regular combustible cigarettes.

Several statistically significant interactions with $\Gamma$ are consistent with the prediction that present bias influences the utility from tobacco products. Subjects who are sophisticated about their present bias on average receive higher (less negative) baseline utility from e-cigarettes and the NRP. We also estimate that for these subjects the FDA warning has a stronger negative impact on the utility from ecigarettes. These results are consistent with the prediction that naïve present-biased subjects place a lower value on products and product attributes related to future utility.

\section{Counterfactuals}

Table 5 presents predicted choices of tobacco products under various counterfactual assumptions about product attributes and consumer optimization errors. The first set of counterfactuals predict consumer choices under policy-relevant changes in product attributes. In most of the counterfactuals relevant to the 2016 FDA deeming regulation, tobacco product choices are not predicted to change much. Under pre-2016 FDA regulation market conditions - many flavors available, 
no warning label, and price of $\$ 6$ - our model predicts that 16 percent of consumers will choose ecigarettes, 71 percent will choose combustible cigarettes, and 13 percent will choose the NRP. Even if the FDA review of new product applications results in an effective ban of flavors, when combined with the new FDA-required label our model predicts that the fraction of consumers who choose e-cigarettes falls only slightly from 16 to 15 percent. This suggests little welfare implications of the FDA's recent actions to remove flavored e-cigarettes from stores accessible to minors. If the FDA were to adopt the stronger warning label, our model predicts that the fraction of consumers who choose e-cigarettes would decrease to 13 percent.

The FDA has recently threatened to eliminate application enforcement discretion to any currently marked e-cigarettes, which would result in a total ban (FDA 2018). A total ban of e-cigarettes is outside the range of the experimental conditions in the DCE. With that caveat in mind, our model predicts that if e-cigarettes were banned the fraction of consumers who choose combustible cigarettes would increase to 82 percent while the fraction who choose the NRP increases to 18 percent.

The counterfactual predictions suggest that policies that change e-cigarette prices will have larger effects on tobacco product choices. Many states are considering and nine states have enacted ecigarette taxes as high as $\$ 4.94$ per pack-equivalent (in D.C.). An e-cigarette tax that increases the price by $\$ 3$ is predicted to decrease the fraction of consumers who choose e-cigarettes to 14 percent. Although policy makers are not currently considering e-cigarette subsidies, in principle they could; for example, state Medicaid coverage for smoking cessation products could be extended to e-cigarettes. An e-cigarette subsidy that decreases the price by $\$ 3$ is predicted to increase the fraction who choose ecigarettes to 30 percent. The asymmetric response to the price increase versus decrease mainly reflects subjects' responses to the DCE experimental conditions and is not driven by functional form assumptions. 
Table 5 also shows descriptive counterfactuals where there are fewer consumer optimization errors. These counterfactuals do not correspond to any plausible policy-relevant scenarios. Instead, they illustrate the magnitudes of the roles the consumer optimization errors play in tobacco product choices. Our model predicts that the fraction of consumers who choose e-cigarettes is about five percentage points higher among: consumers who have correct perceptions of e-cigarette and NRP risks; or among consumers who are not naïve about their present bias. The fraction of consumers who choose ecigarettes is predicted to increase from the baseline of 16 percent to 32 percent among consumers who make neither optimization error, while the fraction who choose combustible cigarettes is predicted to decrease from 71 percent to 42 percent. The descriptive evidence from these counterfactuals that show large differences across consumer groups defined by their optimization errors are useful and important, in the same way descriptive evidence about gender or race differences can be. ${ }^{16}$

\section{Welfare Analysis}

The last four columns in Table 5 present the CVs in income for the policy counterfactuals, compared to the pre-2016 FDA regulation market conditions. For our standard welfare analysis, we calculate one set of CVs defined in equation (8) with respect to decision utility. For our behavioral welfare analysis, we calculate another set of CVs defined in equation (10) with respect to experienced utility. We calculate the CVs averaged over all subjects in our sample. The average CVs include the zero values for subjects who are not at the margin and choose combustible cigarettes regardless of the policy-induced changes in e-cigarette attributes. To shed light on the distribution of CVs, Table 5 also reports the CVs per e-cigarette user.

\footnotetext{
${ }^{16}$ Our experimental design does not allow us to identify the causal effects of the optimization errors. An interesting direction for future work would be an experiment such as information provision to reduce subjective risk misperceptions. $\beta$-discounting and naïveté might be more-or-less unchangeable preference parameters that cannot be manipulated in an experiment or by policy. However, future work might explore nudges such as framing that could lead to fewer optimization errors even if the preference parameters remain stable.
} 
The difference between the CVs calculated with respect to decision versus experienced utility shows the importance of conducting behavioral welfare economics that accounts for optimization errors. In general, the CVS with respect to experienced utility are about twice as large (in absolute value) as the CVs with respect to decision utility, and in some cases even larger. The CV for the FDA warning with respect to experienced utility is $\$ 0.12$ per subject or $\$ 0.25$ per e-cigarette user, triple the size of the CV with respect to decision utility. This pattern reflects the estimated interaction with $\Gamma$, where sophisticated subjects respond more strongly to the FDA warning.

Because consumer optimization errors lead to too few smokers choosing e-cigarettes, standard estimates of the costs of FDA e-cigarette regulations will substantially under-state the behavioral welfare economic-based estimate of costs. Conversely, the standard approach to estimate the benefits of a policy like a subsidy that increases e-cigarette use will substantially under-state the behavioral economic-based benefits estimate. Back-of-the-envelope calculations help illustrate the practical importance of behavioral cost-benefit analysis. Suppose that each of the 36.5 million adult smokers in the U.S. makes a tobacco product choice once per week. In our behavioral welfare analysis we estimate that a ban of e-cigarettes (the most extreme regulatory outcome) imposes a welfare cost of $\$ 1$ per smoker per choice, so the total annual costs of the ban are $\$ 1.9$ billion. From a standard welfare analysis, the per smoker per choice cost is $\$ 0.49$ and the total costs are only $\$ 930$ million. Our estimates of the impact of e-cigarette regulations on consumer welfare contribute to recent research on the behavioral welfare economic analysis of tobacco control (Ashley, Nardinelli and Lavaty 2015, Cutler et al. 2016, Jin et al. 2015, Levy, Norton and Smith 2016).

\section{Discussion}

In this article we use novel data from a DCE to study consumer choices about e-cigarettes. Our policy and behavioral welfare analysis suggests that the 2016 FDA deeming regulation might be mostly harmless: the regulation's direct requirements are not predicted to change consumer choices or welfare 
very much. However, potential future FDA regulations and state tax and subsidy policies could result in larger changes in the intertwined markets for e-cigarettes and combustible cigarettes. Our results suggest that because of consumer optimization errors, many smokers fail to choose e-cigarettes even though that choice would increase their experienced utility. Potential policies like strong warning labels and e-cigarette taxes that further discourage use of e-cigarettes could move consumers even further away from optimal choices and lead to potentially large consumer welfare losses. Conversely, an ecigarette subsidy could help align actual choices with the choices that maximize experienced utility and yield large consumer welfare gains.

Our DCE provides stated preference data on consumer choices under e-cigarette market conditions not yet observed. As the FDA regulatory process unfolds, it might create opportunities to study consumer choices in revealed preference data from observed markets. Analysis of revealed preference data will face difficult identification challenges. The difference-in-difference approach can be used to study some e-cigarette policies. For example, several recent studies provide evidence that state minimum age laws and indoor vaping restrictions increase smoking of combustible cigarettes (Friedman 2015, Pesko, Hughes and Faisal 2016, Dave, Feng, and Pesko, 2019, Pesko and Currie 2016, Cooper and Pesko 2017). However, there will not be state-level policy variation to identify the impact of the requirements of the FDA deeming regulation (which include a national minimum purchase age) or of future FDA regulatory actions such as new product standards to lower nicotine levels in combustible cigarettes to non-addictive levels (FDA 2017). Future research on these policies might use data from additional DCEs or combine data from DCEs with revealed preference data from observed markets. In addition to the changes in product attributes and consumer choices we study, FDA regulations might have important supply-side effects. After a grace period, the deeming regulation requires e-cigarette manufacturers to submit marketing applications in order to continue to sell their products. The FDA (2016) estimates that in response to the market application costs, between 50 and 
87.5 percent of current manufacturers of e-liquids and 50 percent of current manufacturers of delivery systems will not enter the new regulated market. Future research could explore the implications of regulation-induced entry costs for market concentration, prices, product variety and ultimately consumer welfare. The FDA could also use its regulatory authority to enact new supply-side regulations. For example, although e-cigarettes are currently advertised on television, the FDA could ban such advertising. Qi (2013) finds evidence that the 1971 ban on cigarette advertising on television contributed to increased concentration in the cigarette industry. Studying the supply-side effects of FDA regulation of the e-cigarette industry poses additional research opportunities and challenges for future research. 
Table 1 Descriptive statistics

\begin{tabular}{lc}
\hline & Mean \\
\hline DCE choices: & \\
E-cigarettes & 0.16 \\
Cigarettes & 0.71 \\
Nicotine replacement products (NRPs) & 0.13 \\
Revealed preference (prior use): & \\
Also use E- cigarettes & 0.17 \\
Use cigarettes only & 0.65 \\
Also use NRPs & 0.18 \\
Selected demographics: & \\
Age 18-24 & 0.44 \\
Female & 0.55 \\
Less than high school & 0.092 \\
High school & 0.35 \\
Some college & 0.39 \\
Bachelor's degree or higher & 0.18 \\
\hline Observations & 1,148 \\
\hline
\end{tabular}


Table 2 Consumer optimization errors

\begin{tabular}{lccc}
\hline & Mean & Min & Max \\
\hline \# deaths out of 100 users of e-cigarettes & 30.1 & 0 & 100 \\
\# deaths out of 100 users of cigarettes & 45.7 & 0 & 100 \\
\# deaths out of 100 users of NRPs & 27.8 & 0.34 & 80.5 \\
-discount (present bias) factor & 0.73 & 0.0082 & 1.24 \\
Little present bias ( $\beta$-discount factor > 0.9) & 0.37 & 0 & 1 \\
Interested in using a Commitment Contract & 0.20 & 0 & 1 \\
\hline Observations & 1,148 \\
\hline
\end{tabular}

Notes: \# deaths out of 100 users of NRPs is derived based on self-reported \# deaths out of 100 users of e-cigarettes and cigarettes and self-reported perceived harm of using e-cigarettes and NRPs (compared to smoking cigarettes). 
Table 3: Reduced-form models of e-cigarette choice

\begin{tabular}{|c|c|c|c|}
\hline & LPM & $\begin{array}{l}\text { Multi- } \\
\text { nomial } \\
\text { Logit }\end{array}$ & $\begin{array}{l}\text { Multinomial Logit with } \\
\text { pooled stated } \\
\text { and revealed } \\
\text { preferences }\end{array}$ \\
\hline \multirow[t]{3}{*}{ Many flavors } & $0.015^{* *}$ & $0.121^{* *}$ & $0.227^{* * *}$ \\
\hline & $(0.005)$ & $(0.037)$ & 0.055 \\
\hline & & {$[0.015]$} & {$[0.028]$} \\
\hline \multirow[t]{3}{*}{ Warnings: FDA } & $-0.012^{*}$ & -0.081 & 0.083 \\
\hline & $(0.006)$ & $(0.044)$ & 0.049 \\
\hline & & {$[-0.010]$} & [0.010] \\
\hline \multirow[t]{3}{*}{ Warnings: Reduced risks } & -0.010 & -0.071 & 0.104 \\
\hline & (0.006) & $(0.044)$ & 0.074 \\
\hline & & {$[-0.009]$} & [0.013] \\
\hline \multirow[t]{3}{*}{ Warnings: MarkTen } & $-0.060^{* * *}$ & $-0.514^{* * *}$ & $-0.327^{* * *}$ \\
\hline & $(0.007)$ & $(0.063)$ & 0.059 \\
\hline & & {$[-0.058]$} & {$[-0.040]$} \\
\hline \multirow[t]{3}{*}{ Price: \$6 } & $-0.125^{* * *}$ & $-0.861^{* * *}$ & $-0.711^{* * *}$ \\
\hline & $(0.009)$ & $(0.061)$ & 0.120 \\
\hline & & {$[-0.099]$} & {$[-0.087]$} \\
\hline \multirow[t]{3}{*}{ Price: $\$ 9$} & $-0.180^{* * *}$ & $-1.446^{* * *}$ & $-1.282^{* * *}$ \\
\hline & $(0.011)$ & $(0.083)$ & 0.091 \\
\hline & & {$[-0.154]$} & {$[-0.156]$} \\
\hline \multirow[t]{3}{*}{ Number of deaths out of 100 users } & $-0.001^{* * *}$ & $-0.015^{* * *}$ & -0.014 \\
\hline & $(0.000)$ & $(0.002)$ & 0.008 \\
\hline & & {$[-0.002]$} & {$[-0.002]$} \\
\hline \multirow[t]{3}{*}{ Little present bias ( $\beta$-discount factor $>0.9$ ) } & -0.000 & 0.008 & \\
\hline & $(0.015)$ & $(0.125)$ & \\
\hline & & {$[0.003]$} & \\
\hline \multirow{3}{*}{$\begin{array}{l}\text { Somewhat interested in a commitment } \\
\text { contract }\end{array}$} & $0.089^{* * *}$ & $0.725^{* * *}$ & \\
\hline & (0.021) & $(0.146)$ & \\
\hline & & [0.077] & \\
\hline Observations (subjects $\times 12$ choices) & 13,136 & 13,136 & 13,136 \\
\hline Dep Var Mean & 0.16 & 0.33 & \\
\hline
\end{tabular}

Notes: Models include indicators for demographic characteristics of younger adults, female, race/ethnic categories, marital status, education levels, household income levels, metropolitan area, and census regions. Numbers in brackets ([ ]) are marginal effect estimates. In the multinomial logit models (columns 2 and 3), the results are relative to the baseline category of cigarette choice. Results for NRP use relative to the baseline category are not reported but are available upon request. Standard errors in parentheses are clustered at the individual level. ${ }^{*} p<0.05,{ }^{* *} p<0.01,{ }^{* * *} p<0.001$ 
Table 4 Mixed logit model of E-cigarette use

\begin{tabular}{|c|c|c|}
\hline & $\begin{array}{c}\text { Random coefficient } \\
\text { Mean }\end{array}$ & Fixed coefficient \\
\hline Intercept for E-cigarettes & $\begin{array}{c}-3.550^{* * *} \\
(0.244)\end{array}$ & \\
\hline Interaction with $\Gamma$ & & $\begin{array}{c}2.322^{* * *} \\
(0.476)\end{array}$ \\
\hline Intercept for NRPs & $\begin{array}{c}-6.911^{* * *} \\
(0.300)\end{array}$ & \\
\hline Interaction with $\Gamma$ & & $\begin{array}{c}2.550^{* * *} \\
(0.408)\end{array}$ \\
\hline Many flavors & $\begin{array}{l}0.274^{* *} \\
(0.102)\end{array}$ & \\
\hline Interaction with $\Gamma$ & & $\begin{array}{c}-0.104 \\
(0.189)\end{array}$ \\
\hline Warnings: FDA & $\begin{array}{l}-0.123 \\
(0.125)\end{array}$ & \\
\hline Interaction with $\Gamma$ & & $\begin{array}{l}-0.495^{*} \\
(0.237)\end{array}$ \\
\hline Warnings: Reduced risks & $\begin{array}{l}-0.193 \\
(0.126)\end{array}$ & \\
\hline Interaction with $\Gamma$ & & $\begin{array}{l}-0.052 \\
(0.235)\end{array}$ \\
\hline Warnings: MarkTen & $\begin{array}{c}-1.604^{* * *} \\
(0.176)\end{array}$ & \\
\hline Interaction with $\Gamma$ & & $\begin{array}{c}0.381 \\
(0.298)\end{array}$ \\
\hline Risk of deaths (negative) & $\begin{array}{c}0.970^{* * *} \\
(0.188)\end{array}$ & \\
\hline Interaction with $\Gamma$ & & $\begin{array}{c}0.373 \\
(1.429)\end{array}$ \\
\hline Price: \$6 (negative) & $\begin{array}{l}0.443^{* *} \\
(0.137)\end{array}$ & \\
\hline Interaction with $\Gamma$ & & $\begin{array}{l}-0.445 \\
(0.261)\end{array}$ \\
\hline Price: \$9 (negative) & $\begin{array}{c}1.068^{* * *} \\
(0.095)\end{array}$ & \\
\hline Interaction with $\Gamma$ & & $\begin{array}{l}-0.735^{*} \\
(0.303)\end{array}$ \\
\hline
\end{tabular}




\begin{tabular}{lc}
\hline & $\begin{array}{c}\text { Random coefficient } \\
\text { Standard deviation }\end{array}$ \\
\hline Intercept for E- cigarettes & $4.402^{* * *}$ \\
& $(0.199)$ \\
Intercept for NRPs & $5.442^{* * *}$ \\
& $(0.264)$ \\
Many flavors & $0.705^{* * *}$ \\
& $(0.128)$ \\
Warnings: FDA & 0.125 \\
& $(0.169)$ \\
Warnings: Reduced risks & 0.311 \\
& $(0.188)$ \\
Warnings: MarkTen & $1.629^{* * *}$ \\
& $(0.186)$ \\
Risk of deaths (negative) & $0.930^{* * *}$ \\
& $(0.091)$ \\
Price: $\$ 6$ (negative) & $1.580^{* * *}$ \\
& $(0.234)$ \\
Price: \$9 (negative) & $1.497^{* * *}$ \\
& $(0.165)$ \\
\hline Observations (subjects $\mathrm{x}$ & 13,760 \\
12 choices) & \\
\hline
\end{tabular}

Notes: The random coefficients on the negative of price and risk variables are assumed to follow log normal distribution; other random coefficients are assumed to follow normal distributions. Standard errors in parentheses. ${ }^{*} p<0.05,{ }^{* *} p<0.01,{ }^{* * *} p<0.001$ 


\begin{tabular}{|c|c|c|c|c|c|c|c|}
\hline & Use & Use & Use & CV w.r.t. & $\begin{array}{c}\text { decision } \\
\text { utility }\end{array}$ & CV w.r.t. & $\begin{array}{c}\text { experience } \\
\text { utility }\end{array}$ \\
\hline & $\begin{array}{c}\text { e- } \\
\text { cigarettes }\end{array}$ & cigarettes & NRPs & $\begin{array}{c}\text { Per } \\
\text { subject }\end{array}$ & $\begin{array}{c}\text { Per e-cig } \\
\text { user }\end{array}$ & $\begin{array}{c}\text { Per } \\
\text { subject }\end{array}$ & Per e-cig user \\
\hline Pre-2016 FDA market conditions & $16 \%$ & $71 \%$ & $13 \%$ & & & & \\
\hline \multicolumn{8}{|l|}{ Policy counter-factuals: } \\
\hline Ban flavors & $16 \%$ & $69 \%$ & $15 \%$ & 0.05 & 0.31 & 0.08 & 0.5 \\
\hline FDA warning & $17 \%$ & $68 \%$ & $15 \%$ & 0.04 & 0.25 & 0.12 & 0.75 \\
\hline Reduced risk warning & $17 \%$ & $68 \%$ & $15 \%$ & 0.03 & 0.19 & 0.06 & 0.38 \\
\hline MarkTen warning & $13 \%$ & $72 \%$ & $15 \%$ & 0.15 & 0.94 & 0.26 & 1.63 \\
\hline$\$ 3 \mathrm{Tax}$ & $14 \%$ & $71 \%$ & $15 \%$ & 0.12 & 0.75 & 0.21 & 1.31 \\
\hline \$3 Subsidy & $30 \%$ & $57 \%$ & $13 \%$ & -0.38 & -2.38 & -0.61 & -3.81 \\
\hline Ban flavors \& FDA waning & $15 \%$ & $70 \%$ & $15 \%$ & 0.04 & 0.25 & 0.11 & 0.69 \\
\hline Ban e-cigarettes & $0 \%$ & $82 \%$ & $18 \%$ & 0.49 & 3.06 & 1 & 6.25 \\
\hline \multicolumn{8}{|l|}{ Consumer optimization error counter-factuals: } \\
\hline Correcting risk misperceptions & $22 \%$ & $60 \%$ & $18 \%$ & & & & \\
\hline Correcting naiveté about time inconsistency & $27 \%$ & $51 \%$ & $22 \%$ & & & & \\
\hline Correcting risk misperceptions \& & $32 \%$ & $42 \%$ & $26 \%$ & & & & \\
\hline Naiveté about time inconsistency & & & & & & & \\
\hline
\end{tabular}

Notes: Per e-cigarette user use the number of e-cigarette users in the baseline pre-FDA market condition. 


\section{Appendix Figure 1: Example Discrete Choice Experiment Choice}

If you were shopping for a tobacco/ nicotine product and these were your only options, which would you choose?

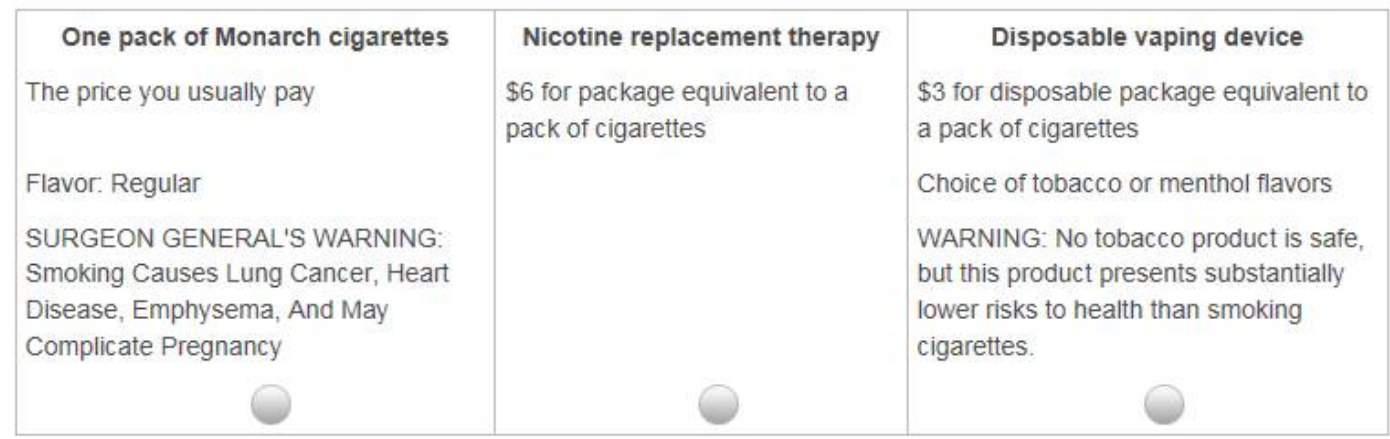


Appendix Table 1: Mixed logit model when $\Gamma$ depends on commitment contract interest and $\beta$ discount factor

Coefficients

(Standard errors)

\section{Mean}

intercept_nrt_commit_somewhat $3.289^{* * *}$

$(0.377)$

intercept_nrt_beta_high $\quad-0.835^{*}$

(0.338)

intercept_ecig_commit_somewhat $2.568^{* * *}$

(0.380)

intercept_ecig_beta_high $\quad 0.102$

(0.363)

flav_many_commit_somewhat $\quad-0.249$

(0.184)

flav_many_beta_high $\quad-0.001$

(0.178)

warn_fda_commit_somewhat $\quad-0.479^{*}$

(0.239)

warn_fda_beta_high $\quad-0.168$

(0.229)

warn_reduced_commit_somewha $\quad-0.031$

$\mathrm{t}$

(0.237)

warn_reduced_beta_high $\quad 0.034$

(0.228)

warn_tough_commit_somewhat 0.482

(0.314)

warn_tough_beta_high $\quad 0.264$

(0.299)

mdie_commit_somewhat $\quad 1.166$

(0.776)

mdie_beta_high 1.439

$(0.800)$

$-0.620^{*}$

$(0.265)$

0.204

(0.244)

$-0.466$

(0.301)

0.160

(0.303)

$-6.420^{* * *}$

$(0.261)$

$-3.816^{* * *}$

(0.301)

$0.341^{* *}$

(0.117) 


\begin{tabular}{ll} 
Warnings: FDA & -0.071 \\
Warnings: Reduced risks & $(0.148)$ \\
& -0.226 \\
Warnings: MarkTen & $(0.149)$ \\
& $-1.916^{* * *}$ \\
mdie & $(0.228)$ \\
& 0.212 \\
mpric_6 & $(0.185)$ \\
& $0.398^{*}$ \\
mpric_9 & $(0.169)$ \\
& $1.231^{* * *}$ \\
\hline Standard Deviation & $(0.112)$ \\
intercept_nrt & \\
& $4.743^{* * *}$ \\
intercept_ecig & $(0.204)$ \\
& $4.562^{* * *}$ \\
Many flavors & $(0.261)$ \\
& $0.564^{* * *}$ \\
Warnings: FDA & $(0.148)$ \\
& 0.019 \\
Warnings: Reduced risks & $(0.179)$ \\
& -0.125 \\
Warnings: MarkTen & $(0.235)$ \\
mdie & $1.825^{* * *}$ \\
mpric_6 & $(0.196)$ \\
& $1.820^{* * *}$ \\
mpric_9 & $(0.110)$ \\
& $-1.746^{* * *}$ \\
& $(0.202)$ \\
& $1.992^{* * *}$ \\
& $(0.328)$ \\
\hline & 40,380 \\
& \\
& \\
&
\end{tabular}


Appendix Table 2: Reduced-form models comparing revealed and stated preference

\begin{tabular}{lll}
\hline & \multicolumn{2}{c}{ Choice of e-cig } \\
\hline & $\begin{array}{l}\text { Revealed Preference } \\
\text { (Standard errors) }\end{array}$ & $\begin{array}{l}\text { Stated Preference } \\
\text { (Standard errors) }\end{array}$ \\
\hline Little present bias & $0.04671^{*}$ & 0.00673 \\
& $(0.02217)$ & $(0.01429)$ \\
Quit interest (scale 1-10) & 0.00006 & $0.01506^{* * *}$ \\
& $(0.00396)$ & $(0.00246)$ \\
Interested in a commitment contract & 0.01172 & $0.06096^{* *}$ \\
\# deaths out of 100 users of e-cig & $(0.02793)$ & $(0.02101)$ \\
& $-0.00204^{* * *}$ & $-0.00183^{* * *}$ \\
Age 18-24 & $(0.00052)$ & $(0.00033)$ \\
& $0.12703^{* * *}$ & $0.09556^{* * *}$ \\
Age 25-39 & $(0.02928)$ & $(0.01743)$ \\
Age 40-54 & 0.05382 & 0.03949 \\
Female & $(0.03678)$ & $(0.02325)$ \\
High school & $0.06920^{*}$ & 0.02045 \\
Some college & $(0.03303)$ & $(0.01830)$ \\
Bachelor's degree or higher & 0.03706 & 0.01481 \\
Constant & $(0.02171)$ & $(0.01362)$ \\
& 0.05523 & 0.00516 \\
Obs & $(0.03936)$ & $(0.02194)$ \\
Dep Var Mean & 0.07592 & -0.01599 \\
Not & $(0.03943)$ & $(0.02194)$ \\
& 0.06736 & 0.01490 \\
& $(0.04398)$ & $(0.02639)$ \\
& -0.02816 & 0.02894 \\
& $(0.05321)$ & $(0.02926)$ \\
\hline & 1,119 & 13,412 \\
& 0.15 & 0.17 \\
\hline
\end{tabular}

Notes: Data from an online survey and a Discrete Choice Experiment (DCE) conducted by GfK. Standard errors in parentheses. ${ }^{*} p<0.05, * * p<0.01, * * * p<0.001$ Standard errors are clustered at the individual level in the stated preference data. 


\section{References}

Abouk, R. \& Adams, S. (2017). “Bans on Electronic Cigarette Sales to Minors and Smoking among High School Students." Journal of Health Economics 54, 17 - 24.

Allcott, H. (2013). “The Welfare Effects of Misperceived Product Costs: Data and Calibrations from the Automobile Market." American Economic Journal: Economic Policy, 5(3), 30 - 66.

Allcott, H., Mullainathan, S., Taubinsky, D. (2014). “Energy Policy with Externalities and Internalities." Journal of Public Economics 112: 72 - 88.

Allcott, H., Taubinsky, D. (2015). “Evaluating Behaviorally-Motivated Policy: Experimental Evidence from the Lightbulb Market." American Economic Review 105 (8): 2501 - 2538.

Angeletos, G-M., Laibson, A., Repetto, A., Tobacman, J., Weinberg, S. (2001). “The Hyperbolic Consumption Model: Calibration, Simulation, and Empirical Evaluation." Journal of Economic Perspectives 15 (3): $47-68$.

Ashley, E. M., Nardinelli, C. \& Lavaty, R. A. (2015). “Estimating the Benefits of Public Health Policies That Reduce Harmful Consumption." Health Economics 24 (5), 617-624.

Augenblick, N., Niederle, M. \& Sprenger C. (2015). “Working Over Time: Dynamic Inconsistency in Real Effort Tasks." Quarterly Journal of Economics, 1067 - 1115.

Biener, L., Hargraves, J. L. (2014). “A Longitudinal Study of Electronic Cigarette Use in a Population-Based Sample of Adult Smokers: Association with Smoking Cessation and Motivation to Quit." Nicotine \& Tobacco Research 17 (2): 127 - 133.

Bhatnagar, A., Whitsel, L. P., Ribisl, K. M., Bullen, C. et al. Chaloupka, F., Piano, R.M.R., Robertson, R. M., McAuley, T., Goff, D., Benowitz, N. (2014). “Electronic Cigarettes: A Policy Statement from the American Heart Association." Circulation 130: 1418-1436. 
Bridges, J.F., Hauber, A.B., Marshall, D., et al. (2011). “Conjoint Analysis Applications in Health a Checklist: A Report of the ISPOR Good Research Practices for Conjoint Analysis Task Force." Value in Health 14 (4): $403-413$.

Carson, R. T. (2012). “Contingent valuation: a practical alternative when prices are not available." Journal of Economic Perspectives 26: 27-42.

Centers for Disease Control and Prevention. State Tobacco Activities Tracking and Evaluation (STATE) System. Available at: https://www.cdc.gov/statesystem

Chetty, R. (2015). "Behavioral Economics and Public Policy: A Pragmatic Perspective." American Economic Review 105 (5): 1 - 33.

Cooper, M. T., and M. F. Pesko. "The Effect of E-Cigarette Indoor Vaping Restrictions on Adult Prenatal Smoking and Birth Outcomes." [In English]. Journal of Health Economics 56 (Dec 2017): 178-90. Courtemanche, C., Heutel, G., McAlvanah, P. (2014). "Impatience, Incentives and Obesity." Economic Journal 125 (582):1 - 31.

Crowley, R. A., for the Health Public Policy Committee of the American College of Physicians. (2015). "Electronic Nicotine Delivery Systems: Executive Summary of a Policy Position Paper From the American College of Physicians." Annals of Internal Medicine 162: 583-584.

Cutler, David M, Amber Jessup, Donald Kenkel, and Martha A Starr (2016). "Economic Approaches to Estimating Benefits of Regulations Affecting Addictive Goods." American Journal of Preventive Medicine 50 (5S1): S20 - S26.

Dave, D., B. Feng, and M. F. Pesko. "The Effects of E-Cigarette Minimum Legal Sale Age Laws on Youth Substance Use." [In English]. Health Economics 28, no. 3 (Mar 2019): 419-36.

Farsalinos, K. E., V. Voudris, and K. Poulas. (2015). "E-Cigarettes Generate High Levels of Aldehydes Only in "Dry Puff' Conditions." Addiction 110, no. 8: 1352-1356. 
Friedman, A. S. (2015). “How Does Electronic Cigarette Access affect Adolescent Smoking?” Journal of Health Economics 44: 300-308.

Food and Drug Administration. (2016). “Deeming Tobacco Products To Be Subject to the Federal Food, Drug, and Cosmetic Act, as Amended by the Family Smoking Prevention and Tobacco Control Act; Restrictions on the Sale and Distribution of Tobacco Products and Required Warning Statements for Tobacco Products; Final Rule." Federal Register, 81 (90): 28974 - 29106.

Food and Drug Administration. (2017). “FDA Announces Comprehensive Regulatory Plan to Shift Trajectory of Tobacco-related Disease, Death." Press Release, July 28, 2017. Available at: https://www.fda.gov/newsevents/newsroom/pressannouncements/ucm568923.htm

Food and Drug Administration. (2018). "Statement from FDA Commissioner Scott Gottlieb, M.D., on proposed new steps to protect youth by preventing access to flavored tobacco products and banning menthol in cigarettes." Statement, November 15, 2018. Available at: https://www.fda.gov/NewsEvents/Newsroom/PressAnnouncements/ucm625884.htm Food and Drug Administration. (2019). "Swedish Match North America, Inc., MRTP Applications." Press Release, February 20, 2019. Available at: https://www.fda.gov/tobaccoproducts/labeling/marketingandadvertising/ucm533454.htm Gine, X., Karlan, D., Zinman, J. (2010). “Put Your Money Where Your Butt Is: A Commitment Contract for Smoking Cessation." American Economic Journal: Applied Economics 2 (4): 213 - 25.

Goniewicz, M. L., Knysak, J., Gawron, M., Kosmider, L., Sobczak, A., Kurek, J., \& Benowitz,N. (2014). "Levels of selected carcinogens and toxicants in vapour from electronic cigarettes." Tobacco Control 23: 133-139.

Gottlieb, S. (2017). “Protecting American Families: Comprehensive Approach to Nicotine and Tobacco." Remarks as prepared for delivery. Commission of Food and Drug Administration. Available online: https://www.fda.gov/NewsEvents/Speeches/ucm569024.htm. (Accessed July 31, 2017). 
Gruber, J., Koszegi, R. (2001). “Is Addiction ‘Rational’? Theory and Evidence.” Quarterly Journal of Economics 116 (4): $1261-1303$.

Hajek, P., A. Phillips-Waller, D. Przulj, F. Pesola, K. Myers Smith, N. Bisal, J. Li, et al. "A Randomized Trial of E-Cigarettes Versus Nicotine-Replacement Therapy." N Engl J Med 380, no. 7 (Feb 14 2019): 629-37.

Hajek, P., Etter, J.-F., Benowitz, N., Eisenberg, T., \& McRobbie, H. (2014). “Electronic cigarettes: Review of use, content, safety, effects on smokers and potential for harm and benefit." Addiction 109: 1801-1810.

Hausman J. (2012). "Contingent valuation: from dubious to hopeless." Journal of Economic Perspectives 26: 43-56.

Jin, L., Kenkel, D., Liu, F., Wang, H. (2015). “Retrospective and Prospective Benefit-Cost Analyses of U.S. Anti-Smoking Policies." Journal of Benefit-Cost Analysis 6 (1): 154 - 186.

Kenkel, D. (2016). “Healthy Innovation: Vaping, Smoking, and Public Policy." Journal of Policy Analysis and Management 35 (2): 473-479.

Kesternich, I., Heiss, F., McFadden, D., Winter, J. (2013). "Suit the Action to the Word, the Word to the Action: Hypothetical Choices and Real Decisions in Medicare Part D." Journal of Health Economics 32 (6): $1313-1324$.

Ketcham, J.D., Kuminoff, N.V., Powers, C. A. (2016). “Estimating the Heterogeneous Welfare Effects of Choice Architecture: An Application to the Medicare Prescription Drug Insurance Market." National Bureau of Economic Research Working Paper 22732.

Laibson, D., Mqaxted, P. \& Repetto, A. (2017). “Estimating Discount Functions with Consumption Choices over the Lifecycle." Working Paper.

Leggett, C.G. (2002). "Environmental Valuation with Imperfect Information." Environmental and Resource Economics 23: 343-355. 
Levy, H., Norton, E.C. \& Smith, J.A. (2016). "Tobacco Regulation and Cost-Benefit Analysis: How Should We Value Foregone Consumer Surplus?" NBER Working Paper 22471.

Levy, D.T., Borland, R., Villanti, A.C., Niaura R., Yuan, Z., et al. (2017). “The Application of a Decision-Theoretic Model to Estimate the Public Health Impact of Vaporized Nicotine Product Initiation in the United States." Nicotine \& Tobacco Research, 149 - 159.

Louviere, J. J., Flynn, T. N., Carson, R. T. (2010). “Discrete Choice Experiments Are Not Conjoint Analysis." Journal of Choice Modelling 3(3): $57-72$.

Marti, J., J. Buckell, J. C. Maclean, and J. Sindelar. "To "Vape" or Smoke? Experimental Evidence on Adult Smokers." Econ Inq 57, no. 1 (Jan 2019): 705-25.

McFadden, D. (2017). "Stated Preference Methods and Their Applicability to Environmental Use and Non-use Valuations." In Contingent Valuation of Environmental Goods: A Comprehensive Critique, McFadden, D. and Train, K. editors. Elgar: Cheltingham. Chapter 6.

McFadden, D. (2017). "Foundations of Welfare Economics and Product Market Applications." NBER Working Paper 23535.

Mullainathan, S., Schwartzstein, J., Congdon, W.J. (2012). “A Reduced-form Approach to Behavioral Public Finance." Annual Review of Economics 4: 511-540.

Newell, R.G., Siikamaki, J. (2015a). “Individual Time Preference and Energy Efficiency.” American Economic Review: Papers \& Proceedings 105 (5): 196 - 200.

Newell, R.G., Siikamaki, J. (2015b). “Nudging Energy Efficiency Behavior: The Role of Information Labels." National Bureau of Economic Research Working Paper 19244.

Pesko, M.F., Currie, J.M. (2016). “The Effect of E-Cigarette Minimum Legal Sale Age Laws on Traditional Cigarette Use and Birth Outcomes among Pregnant Teenagers." NBER Working Paper 22792. 
Pesko, M.F., Hughes, J. M., Faisal, F.S. (2016). "The Influence of Electronic Cigarette Age Purchasing Restrictions on Adolescent Tobacco and Marijuana Use." Preventive Medicine 87: 2017 212.

Pesko, M. F., Kenkel, D., Wang, H., Hughes, J. M. (2015). “The Effect of Potential Electronic Nicotine Delivery System Regulations on Nicotine Product Selection." Addiction 111: 734-744.

Qi, S. (2103). "The Impact of Advertising Regulation on Industry: The Cigarette Ban of 1971." Rand Journal of Economics 44 (2): 215-248,

Ribisl, K., Seidenbert, A. B., \& Orlan, E. N. (2016). “Recommendations for U.S. public policies regulating electronic cigarettes." Journal of Policy Analysis and Management 35, no. 2: 479-89.

Royal College of Physicians (2016). Nicotine without smoke: Tobacco harm reduction. London: RCP.

Schoenborn, C.A., Gindi, R.M. (2015). “Electronic Cigarette Use Among Adults: United States, 2014." NHCS Data Brief Number 217.

Shiffman, S., Ferguson, S.G., Rohay, J. Gitchell, J.G. (2008). “Perceived Safety and Efficacy of Nicotine Replacement Therapies among US Smokers and Ex-smokers: Relationship with Use and Compliance." Addiction 103 (8): 1371 - 1378.

Small, K.A., Rosen, H.S. (1981). “Applied Welfare Economics with Discrete Choice Models.” Econometrica 49 (1): 105-130.

Train, Kenneth E. (2002). Discrete Choice Models with Simulation. Cambridge: Cambridge University Press.

Train, K.E. (2015). "Welfare Calculations in Discrete Choice Models When Anticipated and Experienced Attributes Differ: A Guide with Examples." Journal of Choice Modelling 16, 15 - 22. 
U.S. Department of Health and Human Services. (2014). The Health Consequences of Smoking50 Years of Progress: A Report of the Surgeon General. Atlanta, GA: U.S. Department of Health and Human Services, Centers for Disease Control and Prevention.

U.S. Department of Health and Human Services (2016). E-Cigarette Use Among Youth and Young Adults. A Report of the Surgeon General. Atlanta, GA: U.S. Department of Health and Human Services, Centers for Disease Control and Prevention, National Center for Chronic Disease Prevention and Health Promotion, Office on Smoking and Health.

Viscusi, W. K. (1990). "Do Smokers Underestimate Risks?" Journal of Political Economy 98, no. 6: 1253-1269.

Viscusi, W. K. (2016). "Risk Beliefs and Preferences for E-Cigarettes." American Journal of Health Economics 2, no. 2: 213-240. 